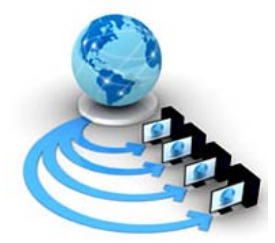

Volume 9, No. 3, May-June 2018

International Journal of Advanced Research in Computer Science

RESEARCH PAPER

Available Online at www.ijarcs.info

\title{
DESIGN AND IMPLEMENTATION OF CONTROL MEACHANISM FOR RAILWAYGATE LEVEL CROSSING
}

\author{
V Arun ${ }^{1}$, D Naresh Kumar', G Manisha² \\ ${ }^{1}$ Department of Electronics and Communication Engineering, \\ MLR Institute of Technology, Hyderabad, India. \\ ${ }^{2}$ Departmentof Electronics and Communication Engineering, \\ Institute of Aeronautical Engineering, Hyderabad, India.
}

\begin{abstract}
The proposed system deals with automatic railway level crossing gate control without the involvement of man power. In this system uses a Bluetooth device which is interfaced with the remote operation achieved by any smart phone. Train driver will send a command from the transmitter which is an android application to close the gate to the Bluetooth device which is controlled by the microcontroller, the command will be executd and the gate will be closed. Once the train moves from the located area the driver will again send the information to the microcontroller to open the gate. This action will be done by using a motor driver IC. In this project we use a Bluetooth as a input which receivers the command from smart phone and output motor through motor driver IC for required operation.
\end{abstract}

Key Words: Bluetooth, Motor, Command (SMS), Control System.

\section{INTRODUCTION}

The present work at the railway level crossing for opening and closing of gate attempts to automatic control of gate without any man power. In general the crossing of the railway gate is manuallyoperated by the gate keeper. Whenever train approaches to the near station the station Inchargewill pass the information to the gate keeper. This is very complex the proposed system deals with automatic railway level crossing gate control without the involvement of man power. In this system uses a Bluetooth device which is interfaced with the remote operation achieved by any smart phone. In this proposed paper we use a Bluetooth as a input which receivers the command from smart phone and output motor through motor driver IC for required operation.

\section{HARDWARE IMPLEMENTATION}

For the hard ware implementation the materials and components used in railway level crossing gate control system are:1. Blue tooth2.Micro controller3.Motor driver IC4. Motor5. Power supply

\section{BLOCK DIAGRAM DESCRIPTION}

A.Bluetooth- This is project is based on the blue tooth HC05 blue tooth module which acts input which receives command from the android application device.

B.Motor driver L293D - L293D is a typical motor driver IC which can control a set of two dc motor in any direction which is a 16 pin IC dual H-bridge motor driver integrated circuit.The logic 00 or 11 input will stop the rotation ofmotor logic 01 and 10 will rotate of motor in clock and anti-clock wise direction respectively.

C.Motor - It is a electrical dc motor that converts electrical energy into mechanical energy. In simple words we can say device which produces rotational forces is motor.

D. Power supply - The power supply required to provide the railwaylevel crossing gate control system is for microcontroller we needed to provide 5VDC and for the motor 12VDC power supply.

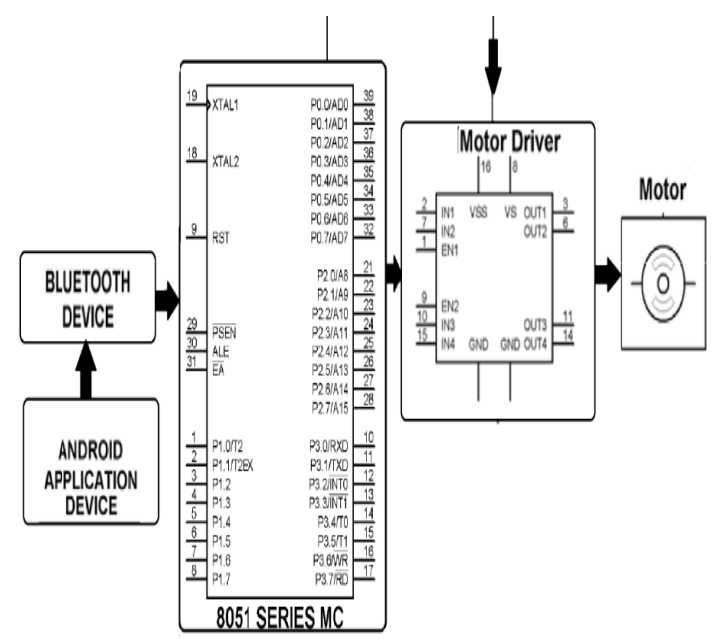

Figure 1: Block diagram [2] 


\section{FLOWCHART AND ALGORITHM}

The steps involved in the flow chart in Figure 2.

Step1: Start

Step2: Checking any data received from inputdevice

Step3:If data received from input is yes then go to step-4 or go to step-2

Step 4: Gate closed

Step 5: If data received from input is no then go to step-2

\section{FLOW CHART FOR RAILWAY GATE CONTROL}

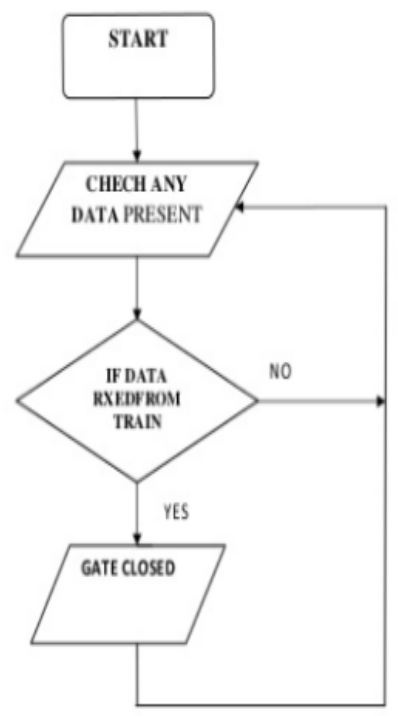

Figure 2. Flow chart of the system [4]

\section{ADVANTAGES, DISADVANTAGES AND APPLICATIONS}

Advantages [4-5]:

- $\quad$ Highly efficient and user friendly design.

- Economy.

- Lifesaving algorithm.

- $\quad$ Easy to operate

- $\quad$ To avoid the human intervention at level crossings completely.

- Reliable machine, which operates even without gatekeeper.

- $\quad$ Prevention of accidents inside the gate.

- $\quad$ Elimination of human error.

- $\quad$ Automatic control system

Disadvantages:

- $\quad$ Not applicable for long distances

- Less accuracy.

Applications:

- $\quad$ Railway gate controlling.

- $\quad$ Parking gate controlling.
- Industries.

- $\quad$ School junctions.

- $\quad$ College junctions.

\section{RESULTS AND DISCUSSION}

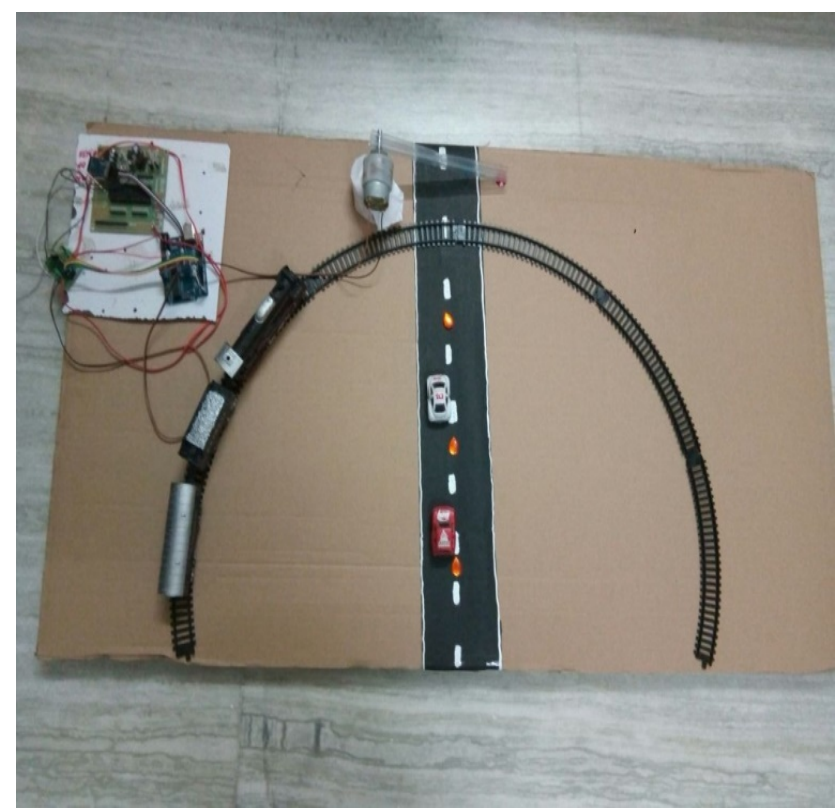

Figure 3.Railway level crossing gate control.

Figure 3 shows the proposed system of railway level crossing gate control this system rules out the need of any human involvement at the railway level crossing gate. A Bluetooth device is interfaced with android with the remote operation achieved by any smart phone. When the information is sent from the input device to the Bluetooth which fed with the microcontroller and sends an output signal to the motor driver IC to active the motor. The status of the gate control, the gate will closed when the motor moves forward direction at certain time.

\section{CONCLUSION}

This paper presents the design and implementation of Railway level crossing gate control system. Railway gate control has been identified to be the main cause of derailments in the past. By this proposed system, the exact location of the faulty rail can easily be located which the will the help of blue tooth mended immediately so that many lives can be saved. By using automatic railway level crossing gate control using blue tooth system we got accuracy up to $80 \%$ distribution.

\section{REFERENCES}

[1]. Muhammed Ali Mazidi ,Janice Gillis pie Mazidi and Rolin McKinley, The 8051 Microcontroller and Embedded System Using Assembly and C.

[2]. Krishna, Shashi Yadav and Nidhi, "Automatic Railway Gate Control Using Microcontroller”, Oriental Journal Of Computer Science \& Technology, Vol.6, No.4, December 2013 
[3]. S. Deepa, N. Thamilarasi, "Automated Unmanned Railway Level Crossing System”, in International Journal of Modern Engineering Research (IJMER), Volume.2, Issue.1, Jan-Feb 2012 pp-45.

[4]. San Franciscos, "Advanced automatic warning signal system” in Proc. CERIE 2010.
[5]. Ahmed Salih Mahdi, Al-Zuhairi, "Automatic Railway Gate and Crossing Control based Sensors \& Microcontroller", International Journal of Computer Trends and Technology (IJCTT), Volume 4, Issue 7, July 2013. 